\title{
Analysis on Surrounding Environment Influence Induced by Rectangular Pipe Jacking and the Control Scheme
}

\author{
Fei WANG ${ }^{\mathrm{a}}$, Songxian $\mathrm{HUANG}^{\mathrm{b}, 1}$ and Wen $\mathrm{CHEN}^{\mathrm{b}}$ \\ ${ }^{a}$ Guangzhou R\&F Properties Co., Ltd., Guangzhou, Guangdong, China \\ ${ }^{\mathrm{b}}$ Department of Civil and Transportation Engineering, Hohai University, Nanjing, \\ Jiangsu, China
}

\begin{abstract}
Based on rectangular pipe jacking project of the No.1 entrance of Qingshi Road station on Wuxi metro Line 4, to analysis how different treating methods work in the aspect of vertical deformation of the pile foundation around the pipe jacking tunnel and the ground settlement during pipe-jacking construction process, a 3-D finite element simulation model which simulate the process of rectangular pipe jacking crossing under viaduct is established. Some conclusions is drawn as follow: (1) the combination of isolation piles and shallow soils grouting reinforcements can constrain the vertical and horizontal deformation of the pile foundation and ground settlement caused by rectangular pipe jacking. (2) Both the maximum ground settlement and maximum ground heave can meet the requirement of special monitoring. (3)The result of the simulation is basically consistent with on-site monitoring data, which can prove the availability of the simulation and the treatment scheme.
\end{abstract}

Keywords. Rectangular pipe jacking, ground deformation, influence analysis

\section{Introduction}

Pipe jacking, which is a typical trenchless construction technology, commonly used in the construction of urban under ground space, have advantages over traditional open cut scheme that it would not influence the traffic and its influence on the soil and existing building in the construction area can be controlled. Compare to circular pipe jacking, rectangular pipe jacking have better adaptability in shallow overburden tunnel excavation and better space utilization [1]. Therefore, more and more engineer apply it in urban shallow overburden tunnel construction.

To apply rectangular pipe jacking in urban underground space, soil disturbance, surface settlement and deflection of existing underground structure cause by pipe jacking construction must be take into consideration. Nowadays, engineers establish three dimension finite element model to evaluate three parameters mentioned above cause by pipe jacking. Numerical simulation performed by J.Yu et al., show soil comprehensive response mechanisms to friction, pipe jacking pressure and soil antiforce in curved circular pipe jacking construction of soft clay [2]. Three dimension

\footnotetext{
${ }^{1}$ Songxian Huang, Department of Civil and Transportation Engineering, Hohai University, Nanjing, Jiangsu, China; E-mail: sx_huang0626@126.com.
} 
finite element analysis result and in-situ monitoring performed by Z. Ji et al., Z.Q. Zhang et al., Z.Y Zhong et al., and T.Liu et al., show how shield tunneling influence existing underground structure under different geological condition and applicability of their finite element simulation in shield tunneling construction [3-6]. Case study conducted by C.M. Deng et al., show surface settlement during shallow overburden rectangular pipe jacking construction in soft soil [7]. T. Wang et al., evaluate the settlement of viaduct's foundation caused by big section rectangular pipe jacking construction with both finite element analysis and in-situ monitoring [8]. The study conducted by people mentioned above show that it is pratical to apply numerical analysis to tunnel excavation process simulation, but they mainly concentrated on adverse effects induced by deep shield tunneling which have different soil reaction with those in shallow depth, or optimization of construction parameters of rectangular pipe jacking. There are few reports on how control measurements such as isolation piles and surface soil grouting work in the aspects of ground subsidence and existing underground structure differential subsidence.

This paper presents a case study of a shallow overburden large-section rectangular pedestrian underpass of a subway station, in order to minimize the subsidence, upheaval, lateral deflection and deformation of surrounding soil and neighboring structure induced by pipe jacking construction, isolation piles installing and surface soil grouting was conducted. To evaluate the effectiveness of control measurements mentioned above, and ensure the successful completion of the project, a preconstruction three dimensional FEM numerical simulation was conducted.

\section{Engineering Profile}

Qingshi road station is the third station from north to south of Wuxi metro line 4 phase I. The station is located at the corner of Qingshi road and Fengxiang road and built along Fengxiang road which run east to west. The pedestrian underpass, being a subway station facility connecting the platform and entrance, was designed to pass beneath the busy Fengxiang Road viaduct. Figure 1 illustrates the plan layout of this pipe jacking project. The minimum distance between the left viaduct pile cap and the underpass is $9.55 \mathrm{~m}$, and the minimum distance between the right viaduct pile cap and the underpass is $11.26 \mathrm{~m}$. Piles foundation of both viaduct pile cap are bored piles with length of about $72 \mathrm{~m}$. Obviously the construction of this tunnel would induce differential subsidence of the viaduct pile caps and settlement or upheaval of the ground, which may make the viaduct structure no longer stable and induce surface ground fracturing. Therefore, to minimize the influence of construction on viaduct structure and surrounding ground, pipe jacking method was selected.

The geotechnical exploration report show that the ground up to a depth of $80 \mathrm{~m}$ mainly consist of fill, clay, clayey silt, clay, clayey silt, clay, silty sand and clay from the top to down. The pipe segment were jacked in first clay layer and the first clayey silt layer. Consider that Fengxiang road is a main road, the thickness of covering soil is design to $4.045 \mathrm{~m}$. Based upon geotechnical exploration report, past experience from similar finished project and the the size of the tunnel etc., the size of the rectangular pipe jacking machine was designed to $7.02 \mathrm{~m} \times 4.32 \mathrm{~m} \times 5.4 \mathrm{~m}$ (width $\times$ height $\times$ length the screw conveyer is not included ), the size of the pipe segment was designed to $1.5 \mathrm{~m}$ long, $7 \mathrm{~m}$ wide and $4.3 \mathrm{~m}$ high with thickness of $0.5 \mathrm{~m}$. The underpass have a total length of $42.65 \mathrm{~m}$ and consists of 28 pipe segments. 


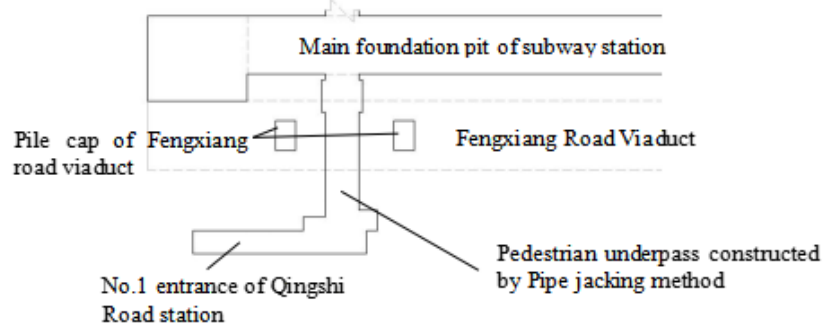

Figure 1. Position relationship between pipe jacking tunnel and neighboring structure.

\section{Numerical Simulation}

\subsection{Numerical Modelling}
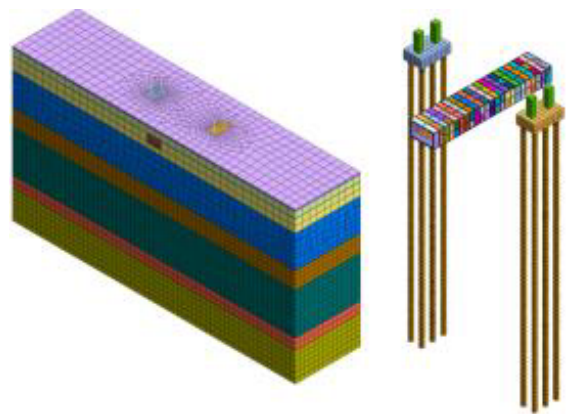

Figure 2. Position relationship between pipe jacking tunnel and neighboring structure

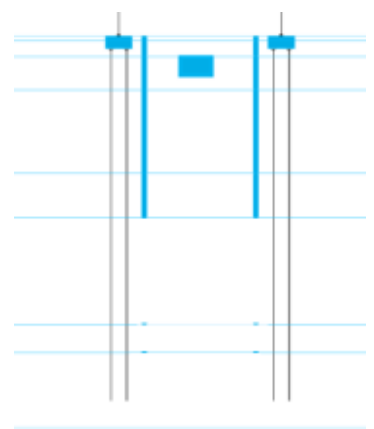

Figure 3. Location sketch for isolation piles.

Figure 2 depicts a 3D FEM numerical model for the project. To evaluate the influence of construction on the surface ground and viaduct, the model was designed to have a length of $150 \mathrm{~m}$, a width of $34.5 \mathrm{~m}$ and a depth of $80 \mathrm{~m}$. The model consists of eight soil layers, the pipe jacking tunnel and piers, pile caps and piles of the viaduct. The top of the tunnel in the model is $4 \mathrm{~m}$ below the ground surface, each pile is $1.2 \mathrm{~m}$ in diameter and have a length of $72 \mathrm{~m}$, the pile caps is $8.6 \mathrm{~m}$ long, $5.4 \mathrm{~m}$ wide with a height of $2.5 \mathrm{~m}$, there are two piers on each pile cap. The piers are $1.5 \mathrm{~m}$ long, $1.5 \mathrm{~m}$ wide and $1.5 \mathrm{~m}$ high.

To analysis the influence of pipe jacking machine on the surrounding soil and neighboring structure under different control measurements, three working conditions was simulated. In working condition 1, no control measurements would be conducted, and the influence of pipe jacking construction on surface ground and the viaduct can be evaluated. In working condition 2, isolation piles with diameter of $1 \mathrm{~m}$ and a length of $24 \mathrm{~m}$ was driven into ground at $2 \mathrm{~m}$ away from the sideline of pile cap of the viaduct, the position relationship among the isolation piles, viaduct, and pipe jacking tunnel is shown in figure 3 . Whether isolation piles can minimize the influence of pipe jacking construction on viaduct was verified in this working condition simulation. In the working condition 3 , to minimize the upheaval of the ground induced by pipe jacking construction, surface ground grouting was conducted on basis of working condition 2 . 


\subsection{The Determination of the Physical Parameters in the Model}

Table 1. Physical parameters of soil layers.

\begin{tabular}{lcccccc}
\hline Soil type & $\boldsymbol{H}(\boldsymbol{m})$ & $\boldsymbol{\gamma}\left(\boldsymbol{k N} / \boldsymbol{m}^{\mathbf{3}}\right)$ & $\boldsymbol{E}(\boldsymbol{M P a})$ & $\boldsymbol{v}$ & $\boldsymbol{\varphi}(\circ)$ & $\boldsymbol{c}(\boldsymbol{k P a})$ \\
\hline Fill & 0.92 & 18.5 & 7500 & 0.30 & 12 & 5.0 \\
Clay-1 & 3.30 & 20.2 & 24930 & 0.33 & 13.4 & 59.3 \\
Clayey silt-1 & 6.80 & 19.0 & 30990 & 0.31 & 29.4 & 8.6 \\
Clay-2 & 17.00 & 20.2 & 22200 & 0.32 & 11.1 & 51.5 \\
Clayey silt-2 & 9.00 & 19.0 & 40080 & 0.31 & 29.0 & 7.0 \\
Clay-3 & 22.00 & 20.0 & 17320 & 0.32 & 9.6 & 19.3 \\
Silty sand & 5.70 & 20.2 & 41840 & 0.30 & 30.6 & 3.9 \\
Clay-4 & 15.30 & 20.1 & 28080 & 0.30 & 13.3 & 62.8 \\
\hline
\end{tabular}

The physical parameters of the soil are shown in table 1. The Mohr-Coulomb constitutive model was applied for the soil. The physical parameters of the structure is shown in table 2 .

Table 2. Physical parameters of structure.

\begin{tabular}{lcccl}
\hline Structure type & $\boldsymbol{\gamma}\left(\boldsymbol{k N} / \boldsymbol{m}^{\mathbf{3}}\right)$ & $\boldsymbol{E}(\boldsymbol{M P a})$ & $\boldsymbol{v}$ & Constitutive model type \\
\hline Pipe jacking machine & 78.0 & 250000000 & 0.2 & Elastic \\
Grouting layer & 22.5 & 10000000 & 0.3 & Elastic \\
Pipe segment & 5.3 & 34500000 & 0.2 & Elastic \\
Pile & 25.0 & 30000000 & 0.3 & Elastic \\
Pile cap & 22.0 & 23400000 & 0.3 & Elastic \\
Pier & 24.0 & 20000000 & 0.3 & Elastic \\
\hline
\end{tabular}

The loads considered in the model have been simplified according to the geotechnical conditions and the related research [9], the factors were as following: the self-weight of the model, the grouting pressure of the bentonite slurry grouting during pipe jacking process and the vertical concentration force applied to each viaduct pier. The determination of jacking force is based on the equations expressed following:

$$
\begin{aligned}
& F=F_{1}+F_{2} \\
& F_{I}=2(a+b) L f
\end{aligned}
$$

In the equations mentioned above, $F$ presents the jacking force, $F_{1}$ presents the friction force between pipe segment and soil, $a$ presents the width of pipe segment, $b$ presents the height of the pipe segment, $L$ presents the length of the pipe segment, $f$ presents the average friction between external surface of pipe segment and soil which range from 2 to $7, F_{2}$ present the front resistance on pipe jacking machine.

\subsection{Numerical Simulation Result Analysis}

When the jacking process was finished. Compared to working condition 1, the maximum upheaval of the ground above the pipe jacking path, increased from $9.87 \mathrm{~mm}$ to $10.61 \mathrm{~mm}$, and the maximum subsidence was decrease from $11.3 \mathrm{~mm}$ to $7.32 \mathrm{~mm}$. The results show that although the installation of the isolation piles would induce ground upheaval in a slight degree, the ground subsidence was decreased significantly.

To analysis the effectiveness of isolation piles on the vertical deformation of the surface ground around the piles cap, a monitoring area with a length of $98 \mathrm{~m}$ was set, 
and the surface ground deformation of this monitoring area when the pipe jacking machine jacked to the middle line of the pile cap under working condition 1 was shown in figure 4 . There are 21 monitoring points set along the connecting line between the centers of the two pile cap in this area, and the midpoint of these monitoring points was center directly over the pipe jacking machine. The surface ground above pipe jacking machine would be uplifted when the machine was jacked through the midpoint mentioned above, and the upheaval was decreased with the increase of the distance from the midpoint. The upward trend of upheaval was suppressed by the piles cap of the viaduct, and the surface ground subsidence was appeared outside the isolation piles.

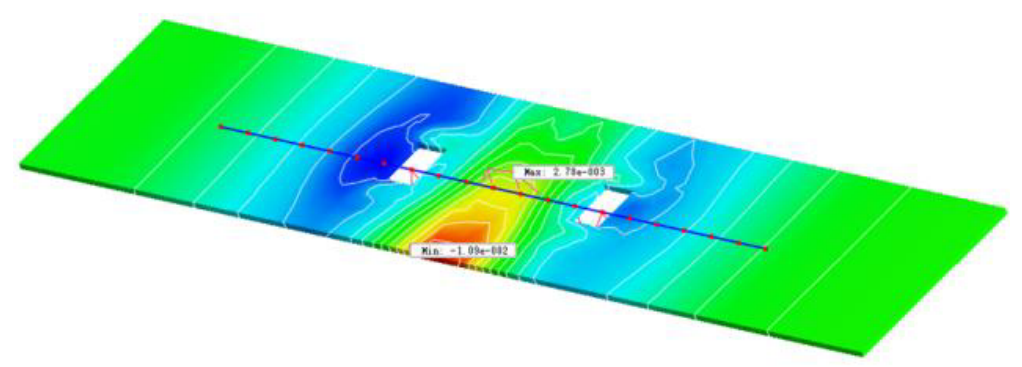

Figure 4. Surface ground deformation when the pipe jacking construction was finished.

Figure 5 depicts the vertical deformation of these monitoring points under both working condition 1 and working condition 2 when the machine was jacked through the midpoint mentioned above. Compare to working condition 1, the subsidence of working condition 2 is decrease from $10.9 \mathrm{~mm}$ to $8.71 \mathrm{~mm}$, and the maximum upheaval was increase from $2.78 \mathrm{~mm}$ to $6.09 \mathrm{~mm}$. This result show that the isolation piles can decrease the subsidence of the surface ground around the pile cap significantly.

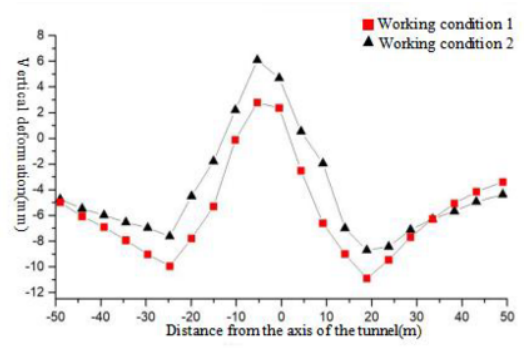

Figure 5. Surface ground deformation when the pipe jacking construction was finished.

As it shown in figure 6, differential subsidence was induced on each pile cap in working condition 1 , and in working condition 2 , differential subsidence of the right pile cap was decreased from $5.41 \mathrm{~mm}$ to $0.86 \mathrm{~mm}$, which means that the installation of isolation pile can decrease the differential subsidence of pile cap itself significantly.

Figure 7 depicts the average differential subsidence between left pile cap and right pile cap during the pipe jacking process, compare to working condition 1 , the differential subsidence was decreased significantly in working condition 2 . 

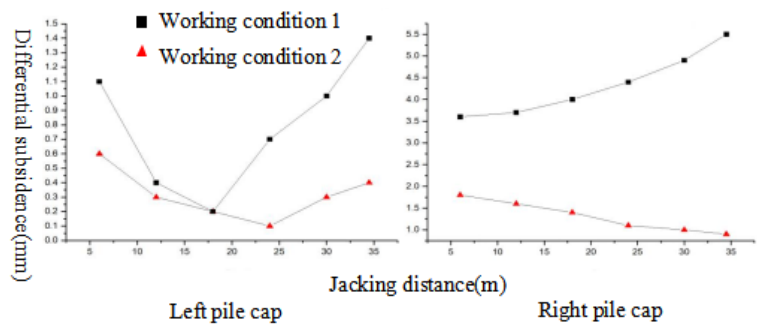

Figure 6. Differential subsidence of each pier cap during the pipe jacking process.

As it shown in figure 5, the isolation pile would increase the surface ground upheaval, and the surface ground upheaval under working condition 2 is over $5 \mathrm{~mm}$, the control value, to offset the ground upheaval, surface ground grouting was conducted on the ground between isolation piles, the grouting depth was $1 \mathrm{~m}$. Compare to working condition 2, the maximum ground subsidence of working condition 3 during the whole pipe jacking process was increase from $9.32 \mathrm{~mm}$ to $9.38 \mathrm{~mm}$, which can meet the requirement of the control value, $10 \mathrm{~mm}$, the ground upheaval was decreased from $6.09 \mathrm{~mm}$ to $4.31 \mathrm{~mm}$, which can also meet the requirement of the control value.

To verified the simulation result, monitoring points was set at the same place in the actual project, figure 8 depicts the ground deformation in all working conditions and the in-situ monitoring, it shows that the trend of ground deformation along with the distance from the midpoint in numerical simulation and in-situ monitoring was very close, the maximum ground subsidence in in-situ monitoring was a little bit over the result in working condition 1 and working condition 3 , but less than $10 \mathrm{~mm}$.

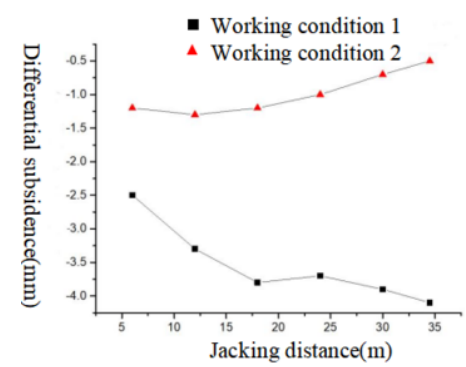

Figure 7. Differential subsidence between the two pile cap.

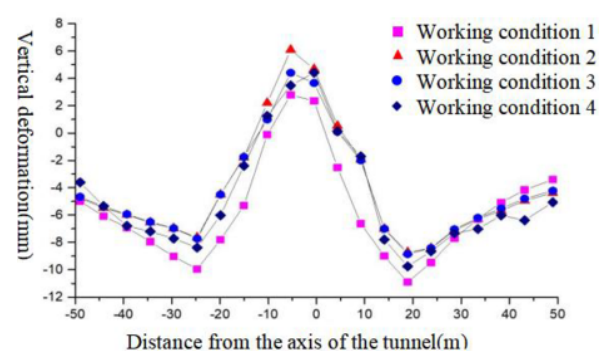

Figure 8. Differential subsidence between the two pile cap.

\section{Conclusion}

To analysis the influence of pipe jacking construction on surrounding ground and neighboring structure and evaluate the effectiveness of isolation piles and the surface ground grouting, a three dimensional FEM numerical model was established, three working conditions was set. The conclusions are summarized as follows:

(1) During the jacking process of shallow overburden rectangular pipe jacking construction, due the to soil-carrying effect, which refers to the constraint of soil arching effect on the shallow covering soil is much less than those in deep depth, so that the shallow covering soil is likely to collapse on the flat top of the rectangular pipe 
segment under gravity when the soil is disturbed by pipe jacking construction, as the pipe jacking machine is jacking forward, the soils on the top of the pipe segment would also be carried forward under friction force, then, ground settlement and ground upheaval would occurred as the pipe jacking machine is jacking forward, and these phenomenon was discovered in both numerical simulation and in-situ monitoring.

(2) The isolation piles can reduce the ground subsidence outside the isolation piles wall and reduce the differential subsidence of the pile cap itself and the differential subsidence between the left pile cap and right pile cap. But the stress release path of soil would be blocked by the isolation pile which would induce ground upheaval.

(3) Surface ground grouting can reduce the ground upheaval induce by pipe jacking construction and installation of isolation piles significantly, and would not aggravate the ground subsidence, the two measurements reduce the influence of pipe jacking construction on the surrounding soil and neighboring structure by a big margin.

\section{Acknowledgments}

The research are supported by the State Key Program of National Natural Science of China (201841830110) and the National Natural Science Foundation of China (51779083).

\section{References}

[1] Peng LM, Wang Z, Ye YC, Yang WC. Technological Development and research status of rectangular pipe jacking method. Tunnel Construction. 2015 Jan; 35(1): 1-8.

[2] Yu J, Gong XN. Numerical analysis of surface settlement control considering pipe jacking construction process. Chinese Journal of Rock Mechanics and Engineering. 2014 Jan; 33(1): 2605-2610.

[3] Ji Z. A Study on Influence of Super-large Rectangular Pipe Jacking through Viaduct Piles in Short Distance in Soft Soil Area. Tunnel and Rail Transit. 2019 Jun; 34(1): 12-15.

[4] Zhang ZQ, He C. Study on the mechanical behaviour of a metro tunnel construction adjacent to existing pile foundations in Shenzhen. Chinese Jounal of Geotechnical Engineering. 2003 Mar; 25(2): 204-207.

[5] Hao ZY, Dai J, Wang G, Xu YF. Settlement analysis of the undercrossing of shield interval into beijing-guangzhou railway construction based on the ANSYS. Highway. 2014 Dec; 59(12): 232-236.

[6] Song XY, Liu T, Liang QK. Deformation of the existing elevated lines of urban rail transit induced by shield tunneling. Railway Engineering. 2011 Jun; 39(6): 65-67.

[7] Deng CM, Peng JM, Shen GH. Discussion on control methods of ground surface settlement caused by rectangular pipe jacking construction in soft soils. Chinese Journal of Underground Space and Engineering. 2016 Aug; 12(4): 1002-1007.

[8] Wang T, Guan GF. Numerical Analysis of Large Diameter Pipe-jacking Construction to Adjacent Existing Viaduct Pile Foundations. Special Structures. 2018 Feb; 35(1): 34-39.

[9] Xue QS. Study on the influence of construction of rectangular box jacking through metro tunnel on ground deformation. Shanxi Architecture. 2020 Jul; 46(15): 9-11. 